\title{
The Rho Pathway Mediates Transition to an Alveolar Type I Cell Phenotype During Static Stretch of Alveolar Type II Cells
}

\author{
CHERIE D. FOSTER, LINDA S. VARGHESE, LINDA W. GONZALES, SUSAN S. MARGULIES, AND SUSAN H. GUTTENTAG
}

Department of Pediatrics [C.D.F., L.S.V., L.W.G., S.H.G.], The Children's Hospital of Philadelphia, University of Pennsylvania School of Medicine, Philadelphia, PA 19104; Department of Bioengineering [S.S.M.], University of Pennsylvania School of Engineering and Applied Science, Philadelphia 19104, PA

\begin{abstract}
Stretch is an essential mechanism for lung growth and development. Animal models in which fetal lungs have been chronically over or underdistended demonstrate a disrupted mix of type II and type I cells, with static overdistention typically promoting a type I cell phenotype. The Rho GTPase family, key regulators of cytoskeletal signaling, are known to mediate cellular differentiation in response to stretch in other organs. Using a well-described model of alveolar epithelial cell differentiation and a validated stretch device, we investigated the effects of supraphysiologic stretch on human fetal lung alveolar epithelial cell phenotype. Static stretch applied to epithelial cells suppressed type II cell markers (SP-B and Pepsinogen C, PGC), and induced type I cell markers (Caveolin-1, Claudin 7 and Plasminogen Activator Inhibitor-1, PAI-1) as predicted. Static stretch was also associated with Rho A activation. Furthermore, the Rho kinase inhibitor Y27632 decreased Rho A activation and blunted the stretch-induced changes in alveolar epithelial cell marker expression. Together these data provide further evidence that mechanical stimulation of the cytoskeleton and Rho activation are key upstream events in mechanotransduction-associated alveolar epithelial cell differentiation. (Pediatr Res 67: 585-590, 2010)
\end{abstract}

$\mathrm{T}_{1}$ he alveolar epithelium is composed of two cell types: type II and type I cells (1). Type II cells are responsible for surfactant production and play a role in lung host defense. Type I cells, although less numerous, cover the majority of the gas exchange surface area of the lung. Development and maintenance of this mixed population of alveolar epithelial cells depend on both the biochemical milieu of growth factors, hormones, and extracellular matrix, and the interplay of physical forces mediated intrinsically by the cytoskeleton and extrinsically by cell-cell and cell-matrix interactions.

Stretch plays a critical role in lung development (2). Static stretch provided by fetal lung fluid provides a constant distending force of approximately $2.5 \mathrm{~mm} \mathrm{Hg} \mathrm{(3).} \mathrm{Fetal} \mathrm{breathing}$ movements provide intermittent cyclic stretch (4) resulting in 3-5\% change in alveolar surface area (3). By comparison, changes in surface area with tidal breathing in adults are minimal (5), whereas expansion to total lung capacity changes surface area by $40-45 \%$ (6). The importance of stretch as a mechanism for lung development has been shown in human

Received September 17, 2009; accepted February 17, 2010.

Correspondence: Susan H. Guttentag, M.D., The Children's Hospital of Philadelphia, Abramson Research Center 416G, 3516 Civic Center Boulevard, Philadelphia, PA 19104; e-mail: guttentag@email.chop.edu

Supported by grants HL-077266 (C.D.F.) and HL059959 (S.H.G.) from the National Institutes of Health. pregnancy complicated by premature membrane rupture (7), in neonatal neuromuscular disorders (8), and in animal models (9).

By extension, enhanced stretch, generally from tracheal obstruction, promotes lung growth $(10,11)$, providing the rationale for the use of tracheal occlusion to reverse pulmonary hypoplasia in congenital diaphragmatic hernia. Although tracheal occlusion increases lung growth through the retention of fetal lung fluid, the effects of this supraphysiologic stretch on differentiation of the alveolar epithelium are less clear (12). Animal studies suggest that static stretch favors the formation of type I cells (13), whereas cyclic stretch favors type II cells (14), but the mechanisms by which stretch is translated into molecular signals to modify gene expression in the alveolar epithelium are poorly understood.

The Rho-GTPase family of small messengers is an attractive candidate for mediating stretch-induced cell signaling because of its tight coupling to the cytoskeleton. As the cytoskeleton is a global receiver and transmitter of mechanical forces (15), Rho-GTP activation could be an early, upstream intracellular event in response to stretch. Rho GTPases have been implicated in lung branching morphogenesis (16), alveolar epithelial permeability (17), migration (18), and recently, maturation of alveolar type II cells (19). We now show, using a validated, equibiaxial stretch device and human fetal lung (HFL) epithelial cells, that changes in epithelial cell phenotype between type I and type II cells with static stretch are associated with activation of the Rho GTPase pathway.

\section{METHODS}

Reagents. Dexamethasone, isobutyl methylxanthine (DCI), and 8-bromocAMP were purchased from Sigma Chemical Co. (St. Louis, MO). All other supplies were purchased from Fisher (Fair Lawn, NJ), Pierce (Rockford, IL) or Invitrogen (Carlsbad, CA). Antisera included SP-B (Chemicon, Temecula, CA), Pepsinogen C (Abcam, Cambridge, UK), Claudin 7 (Zymed, South San Francisco, CA), Plasminogen Activator Inhibitor-1 (BD Transduction Laboratories, Lexington, KY), Caveolin- $1 \alpha$ (Santa Cruz Biotechnologies, Santa Cruz, CA), and Glyceraldehyde-3-phosphate dehydrogenase (GAPDH) (Chemicon).

Cell culture. HFLs from 14- to 18-wk therapeutic abortions were obtained from Advance Bioscience Resources, Inc. (Alameda, CA) and used in protocols approved by the Committee for Human Research at The Children's Hospital of Philadelphia. A stable population of alveolar type II cells (with an

Abbreviations: DCI, Dexamethasone, isobutyl methylxanthine, and 8-bromocAMP; GAPDH, Glyceraldehyde-3-phosphate dehydrogenase; PGC, Pepsinogen C; PAI-1, Plasminogen Activator Inhibitor-1; ROCK, Rho kinase; SP-B, Surfactant Protein B; HFL, human fetal lung 
average $10 \%$ contaminating fibroblasts, $<5 \%$ endothelial cells, and no inflammatory cells) were prepared as described previously (20) and plated at a density of $7 \times 10^{5}$ cells $/ \mathrm{cm}^{2}$ on deformable silastic membranes (Specialty Manufacturing, Saginaw, MI) coated with $50 \mu \mathrm{g} / \mathrm{mL}$ of fibronectin (BD Biosciences, Medford, MA) and mounted into custom-made wells. Waymouth's media containing $10 \mathrm{nM}$ dexamethasone, $0.1 \mathrm{mM}$ 8-bromo-cAMP, and $0.1 \mathrm{mM}$ DCI was used to maintain the type II cell phenotype.

Equibiaxial stretch. Cells on silastic membranes were mounted onto individual cell-stretching devices capable of applying static equibiaxial strain, as described previously (6). Seventy-two hours after plating, cells were stretched continuously for $24 \mathrm{~h}$ at either 10 or $37 \%$ change in surface area. These equibiaxial deformations correspond to static stretches in isolated rat lungs at 55 and $100 \%$ of total lung capacity, respectively.

Cell viability and apoptosis. Ethidium homodimer-1 and calcein AM were added to the wells to assess cell viability (LIVE/DEAD, Molecular Probes, Eugene, OR). Apoptosis was assessed by immunoblotting for activated caspase 3 (R and D Systems, Minneapolis, MN). Cells treated with $1 \mu \mathrm{M}$ Staurosporine (Sigma Chemical Co.) served as a positive control.

Western immunoblotting. Cells were harvested in lysis buffer (1\% Triton $\mathrm{X}-100,150 \mathrm{mM} \mathrm{NaCl}, 50 \mathrm{mM}$ Tris- $\mathrm{HCl}, 5 \mathrm{mM}$ ethylenediamine tetraacetic acid, $5 \%$ glycerol, $\mathrm{pH} 8.0$ ) with $1 \times$ Protease inhibitor (Roche, Indianapolis, IN), and samples immunoblotted using NuPAGE Bis-Tris gels (Invitrogen). Primary antibody concentrations were SP-B 1:4000; PGC 1:5000; Claudin 7, PAI-1, and Caveolin 1 at 1:1000; GAPDH at 1:20,000. Secondary antibodies conjugated to Alexa Fluor 680 (Molecular Probes) or IRdye 800 (Rockland, Gilbertsville, PA) were used at a dilution of 1:10,000. Membranes were analyzed using the Odyssey infrared imaging system (Li-Cor, Lincoln, NE).

Real-time reverse transcriptase PCR. Total cellular RNA was isolated using RNA STAT-60 Reagent (Tel-Test, Friarswood, TX). Purity was verified by the OD 260:280 ratio and integrity assessed using the Agilent 2100 bioanalyzer system (Agilent, Palo Alto, CA). Real-time (RT) PCR assays using a singleplex strategy were done using an ABI Prism 7900 system (ABI, Foster City, CA). Details of the two-step protocol have been described previously (21). The primer/probe sets (listed on the ABI website; available at: http://www.allgenes.com) were SP-B Hs00167036, PGC Hs00160052, claudin 7 Hs00600772, PAI-1 Hs00167155, Cav-1 Hs00184697, and 18s Hs99999901_S1. Standards for comparison of RT-PCR results were derived

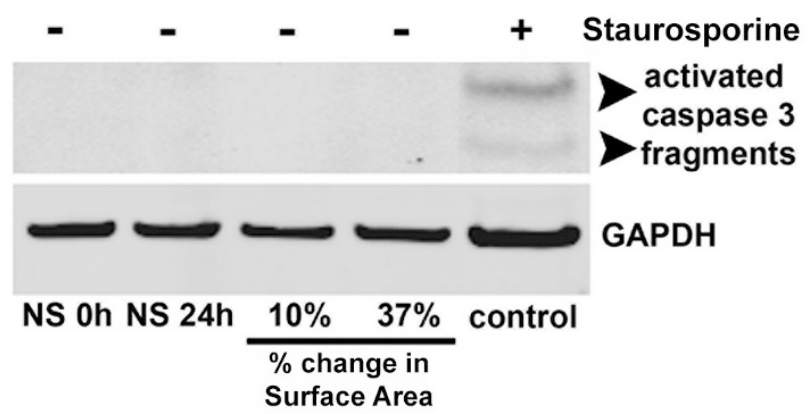

Figure 1. Apoptosis during static stretch. Representative immunoblot for activated caspase 3 in type II cells after $24 \mathrm{~h}$ of no stretch (NS), 10 or $37 \%$ stretch. Staurosporine-treated type II cells served as a positive control. Equal loading was confirmed with GAPDH. from RNA isolated from alveolar type II cells cultured from HFL or from banked frozen adult human lung tissue.

Immunofluorescence imaging. Experimental membranes with adherent cells were mounted on glass slides using Fluoromount (Sigma Chemical Co.). Cells were fixed with $1 \%$ paraformaldehyde in phosphate-buffered saline, and immunostained with Claudin 7 antibody (1:100). Nuclei were counterstained with DAPI. Fluorescence was examined at $20 \times$ with an Olympus IX81 microscope and Slidebook 4.2.0 digital microscopy software (Olympus, San Diego, CA).

Stress fiber analysis. Alexa Fluor 549 Phalloidin (Molecular Probes, Eugene, OR) was used to stain the actin cytoskeleton at the end of the stretching period. Stress fibers were counted in seven random high power fields $(60 \times)$ per treatment group using Image Pro-Plus software (Version 6.0, MediaCybernetics Inc, Bethesda, MD) to determine mean stress fiber intensity per cell.

Rho inhibition. Y27632, a selective Rho kinase (ROCK) inhibitor (Tocris, Ellisville, MO) was added to cells at a concentration of $20 \mu \mathrm{M} / \mathrm{mL}, 1 \mathrm{~h}$ before stretch and maintained throughout the experiment. Direct activation of Rho was assessed using the G-Lisa Rho A Activation Assay (Cytoskeleton, Denver, CO), which measures activated Rho-GTP, per the manufacturer's instructions.

Statistical analysis. Results are expressed as mean \pm SE. Analysis of variance (for LIVE/DEAD) and $t$ tests (all other experiments) were performed with GraphPad Prism 5.0 for Macintosh (GraphPad, San Diego, CA). All protein and RNA studies were normalized with GAPDH and 18S, respectively.

\section{RESULTS}

Static stretch modified alveolar epithelial cell phenotype without cell toxicity. Random field counting ( $n=4$ experiments) revealed no changes in cell viability because of culture or stretch (before stretch $92.8 \pm 2.6 \%$ live cells; no stretch 24 h $91.6 \pm 1.2 \% ; 10 \%$ stretch 24 h $94.0 \pm 1.1 \% ; 37 \%$ stretch 24 h $93.8 \pm 2.4 \% ; p>0.05$ ), and there was no evidence of apoptosis after static stretch (Fig. 1). RT-PCR revealed decreased expression of the type II cell markers SP-B and PGC (Fig. $2 A$ ) at $10 \%$ (SP-B: $61 \pm 8 \%$ and PGC: $50 \pm 5 \%$ of unstretched control) and $37 \%$ change in surface area (SP-B: $50 \pm 5 \%$ and PGC: $51 \pm 7 \% ; n=5-7, p<0.01)$. These changes were not evident at the protein level (Fig. $2 B$ and $C$ ). Induction of RNA for the type I cell markers Claudin 7 and PAI-1 (Fig. 3A) occurred at both 10\% (Claudin 7: $1.5 \pm$ 0.09-fold and PAI-1: $2.0 \pm 0.04$-fold versus unstretched) and $37 \%$ change in surface area (Claudin 7: $1.8 \pm 0.1$-fold and PAI-1: $3.4 \pm 0.4$-fold; $n=3, p<0.05$ ). There was a modest induction of Caveolin-1 RNA with $10 \%$ stretch that did not reach statistical significance $(n=3, p=0.08)$. Immunoblotting demonstrated induction of PAI-1 and Caveolin-1 protein with 37\% stretch (Fig. 3B and C; $n=4-5, p<0.05$ ), and a
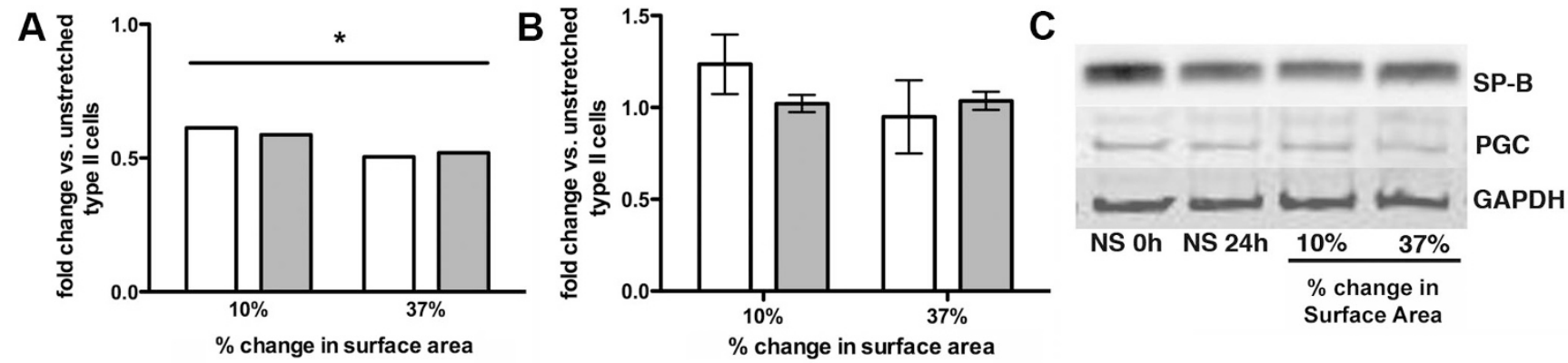

Figure 2. Alveolar type II cell markers during with static stretch. A, Graphic representation of RT-PCR results from five to seven experiments for SP-B (open bars) and PGC (shaded bars) mRNA at $10 \%$ and $37 \%$ static stretch for $24 \mathrm{~h}$, normalized to $18 \mathrm{~S}$ rRNA ( ${ }^{*} p<0.01 v s$ no stretch). B, Immunoblot densitometry, normalized to GAPDH, and $C$, representative immunoblot. 

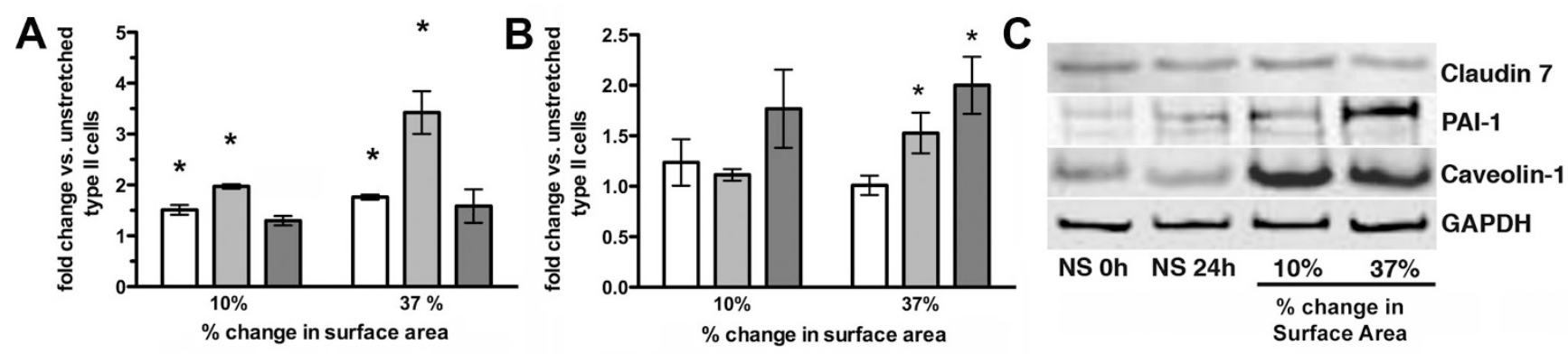

Figure 3. Alveolar type I cell markers during with static stretch. A, Graphic representation of real-time CR results from three to four experiments for Claudin 7 (open bars), PAI-1 (light bars), and Caveolin-1 (dark bars) at both 10 and 37\% stretch for $24 \mathrm{~h}$, normalized to $18 \mathrm{~S}$ rRNA ( $* p<0.05 v s$ no stretch). B, Immunoblot densitometry, normalized to GAPDH ( ${ }^{*} p<0.05 v s$ no stretch), and $C$, representative immunoblot.

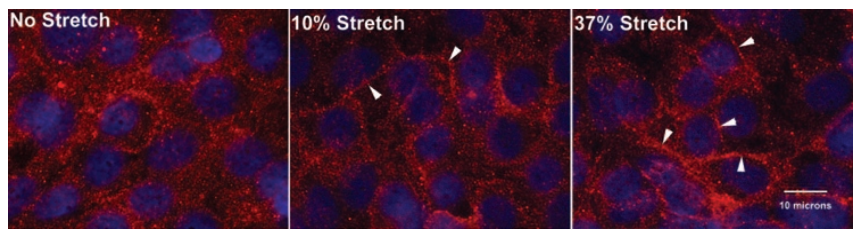

Figure 4. Claudin 7 localization in response to static stretch. Representative images were taken at $\times 60$ of Claudin 7 immunostaining (red; DAPI staining of nuclei, blue) in cells after $24 \mathrm{~h}$ of no stretch $(A), 10 \%(B)$, or $37 \%(C)$ stretch. Plasma membrane distribution of Claudin 7 is shown (arrowheads; $n=2$ experiments, duplicate slides, 4 fields each).
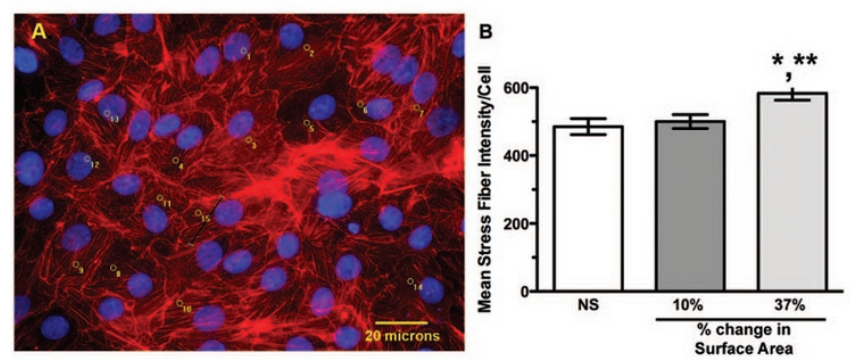

Figure 5. Stress fiber formation in response to static stretch. A, Representative image taken at $20 \times$ of cells after $24 \mathrm{~h}$ of $37 \%$ stretch. Phalloidin-stained stress fibers are red, DAPI-stained nuclei are blue. Image analysis software markings on counted cells appear in yellow, and the black line (cell 15) illustrates a representative stress fiber fluorescent signal density measurement. $B$, Graphic representation of mean fluorescent stress fiber intensity per cell ( $n=3$ experiments, ${ }^{*} p<0.05$ vs NS, $* * p<0.05$ vs $10 \%$ ).

modest increase in Claudin 7 protein expression with $10 \%$ stretch. We characterized Claudin 7 localization to the plasma membrane as a proxy for alveolar epithelial barrier changes because the silastic membranes precluded traditional permeability testing. Claudin 7 was distributed throughout the cytoplasm before stretch (Fig. 4A) and in unstretched cells (not shown). With static stretch (Fig. $4 B$ and $C$ ), Claudin 7 immunostaining was more prominent at the plasma membrane.

Rho-GTP function in response to static stretch. Stress fibers are longitudinal bundles of contractile actin-myosin filaments resulting from activation of the Rho-GTP/ROCK pathway (22). Stress fibers (as shown in Fig. 5A) are present in most cultured cells but are markedly increased by stretch (23). There was a $27 \%$ increase in the mean intensity of phalloidin-positive stress fibers per cell at $37 \%$ stretch compared with unstretched controls (Fig. 5B; $n=3, p<0.05$ ), whereas no significant change was observed at $10 \%$ stretch.

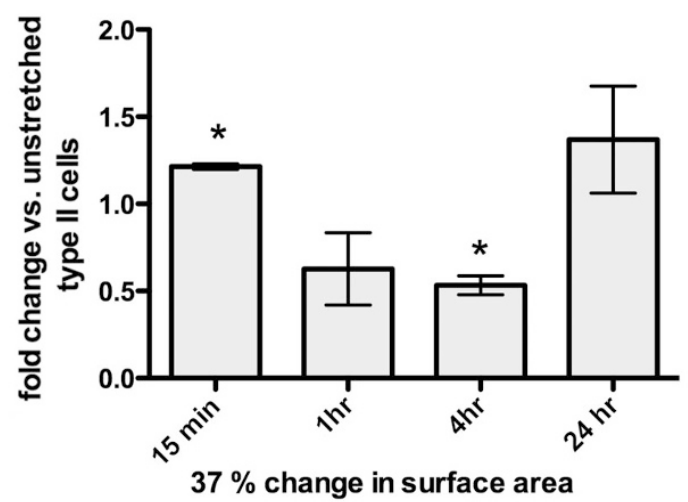

Figure 6. Rho activation in response to static stretch. Time course of Rho-GTP by G-Lisa after initiation of 37\% static stretch $(n=3-4$ experiments, $\left.{ }^{*} p<0.01\right)$.

Because stress fibers are a late endpoint in Rho pathway activation, we measured direct Rho/ROCK pathway activation by ELISA in response to $37 \%$ stretch (Fig. 6). Activated Rho-GTP increased by $21.4 \pm 1.5 \% 15$ min after initiation of $37 \%$ stretch $(n=3-4, p<0.01)$, followed by a decrease at 1 and $4 \mathrm{~h}$ (at 4 h: $46.7 \pm 5.4 \%, n=4, p<0.01$ ), with variable rebound to baseline by $24 \mathrm{~h}$.

Inhibition of Rho diminishes stretch phenotype changes. To determine whether the stretch induced changes in gene expression could be due to activation of Rho, we used a selective Rho inhibitor, Y27632, during epithelial cell stretch (Fig. 7). Y27632 partially restored SP-B RNA expression at $10 \%$ stretch but not at $37 \%$ stretch $(n=4, p<0.05$ versus $10 \%$ stretch without inhibitor). By comparison, expression of PAI-1 was blunted at both $10 \%$ and $37 \%$ stretch in the presence of Y27632 ( $n=4-5, p<0.05$ versus no inhibitor).

\section{DISCUSSION}

Mechanical forces are important regulators of organogenesis and differentiation during fetal development. Although reduced stretch results in lung hypoplasia while overdistention stimulates lung growth (3), the effects of stretch on differentiation have been less clear. Animal models suggest that static stretch promotes type I cell phenotype (13), and cyclic stretch promotes type II cell phenotype (24). More recent studies of animal models of congenital diaphragmatic hernia and postmortem human studies suggest that despite improved lung 


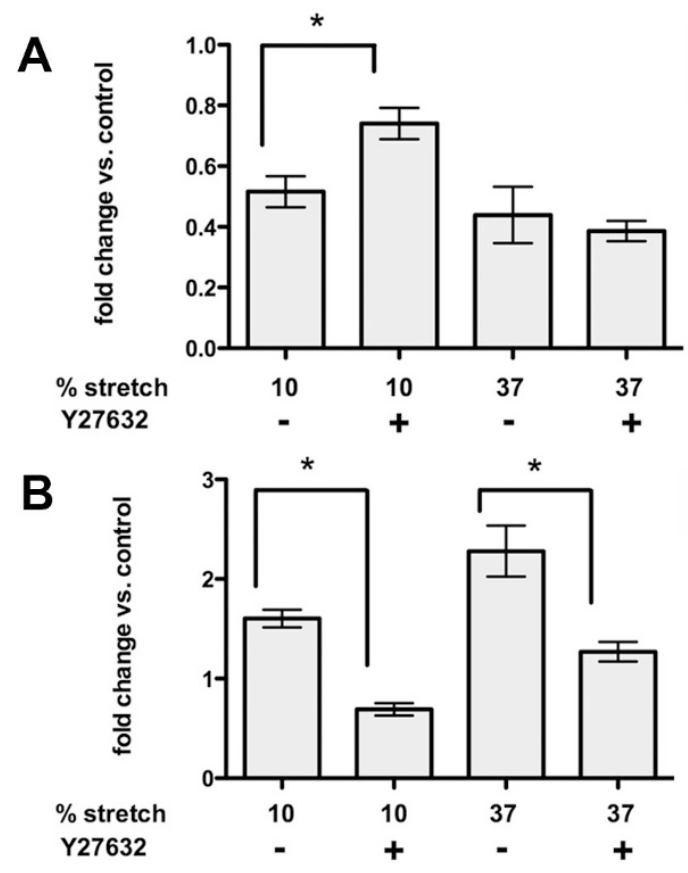

Figure 7. Alveolar epithelial marker expression in response to ROCK inhibition during stretch. Graphic representation of RT-PCR results from four to five experiments for (A) SP-B and (B) PAI1 mRNA after $24 \mathrm{~h}$ of $37 \%$ static stretch in the presence or absence of the ROCK inhibitor Y27632, normalized to $18 \mathrm{~S}$ rRNA $(* p<0.05)$. Cells were pretreated with Y27632 for $1 \mathrm{~h}$ before initiating stretch.

growth, supraphysiologic stretch in utero does not result in a mature alveolar epithelium with an appropriate mixed population of type I and type II cells $(25,26)$. This is the first study to assess the impact of supraphysiologic stretch on alveolar epithelial cell differentiation using a well-characterized model of type II cells derived from HFL in which both the local effects of static stretch and alterations in intracellular pathways can be easily monitored.

Mechanistic studies of stretch-induced epithelial differentiation have been hampered by controversy surrounding alveolar epithelial cell lineage and alveolar epithelial marker expression. The classic dogma-alveolar type II cells as the progenitor for terminally differentiated alveolar type I cellscame from interpretations of older studies using electron microscopy to understand the resolution of lung injury (27). These early studies were supported by later evidence that type II cells served as progenitors for injured type I cells in mature lung (28) and that isolated type II cells in culture for over $24 \mathrm{~h}$ to lose characteristics of type II cells and adopt features of type I cells in the absence of serum (29). Another obstacle to understanding the impact of stretch on differentiation is the paucity of markers that clearly differentiate type I from type II cells across species. Markers such as T1 $\alpha$ (30) and RTI40 (31), now recognized as podoplanin, have not been useful in human lung. Markers that clearly distinguish type I cells from type II cells, such as Caveolin 1, are also found in other cells locally in the lung (32). Antibodies to markers in rodent models have poor crossreactivity to human cells. This study attempts to solve these problems by using a relevant human model and choosing markers that have been reproducible in this and other human models. Our well-characterized cell culture model has been used to examine the cell biology and biochemistry of alveolar type I and II cells (20,33-35). Cells are derived from HFL making this model particularly relevant to lung development. The primary cultures have been consistently $\sim 90 \%$ pure, with contamination chiefly from fibroblasts. However, the use of a human cell culture model restricts the choice of available type I cell markers. We have previously shown that PAI-1, Caveolin 1, and Claudin 7 are robust, reproducible markers of type I cells in this system (34). Although not exclusively expressed by type I cells in the lung, they are clearly not expressed by human type II cells or by contaminating fibroblasts. Therefore, our choice of cell culture system and markers provide a robust model to study the effects of stretch on human fetal alveolar epithelial cell phenotype.

Equibiaxial stretch of type II cells had very predictable effects on the epithelial cell markers. We demonstrated a decline in SP-B and PGC RNA within $24 \mathrm{~h}$ of initiating both $10 \%$ and $37 \%$ stretch, concomitant with an increase in PAI-1 and Caveolin 1 RNA. Compared with our prior report of epithelial cell marker expression in transdifferentiation experiments (34), the decline in type II cell markers with stretch despite the presence of hormones was blunted yet significant. In the prior study, DCI withdrawal effectively eliminated SP-B and PGC RNA expression by $96 \mathrm{~h}$, with persistence of some SP-B protein through $120 \mathrm{~h}$ and PGC protein through $96 \mathrm{~h}$. Persistence of type II cell proteins after cessation of RNA expression has been commonly reported in rodent models of alveolar epithelial cell transdifferentiation $(36,37)$. Importantly, despite culture conditions that should sustain type II cell marker expression, specifically the presence of glucocorticoid and cAMP, stretch significantly impaired SP-B and PGC expression.

Few studies of the effects of stretch on alveolar epithelial cell differentiation have examined type I cell markers (31). In this study, type I cell markers behaved as predicted, increasing in response to $24 \mathrm{~h}$ of static stretch as type II marker expression waned. The magnitude of changes in type I markers was less than we observed by transdifferentiation previously. Claudin 7 was helpful in this study because of its type I cell specificity specific in HFL $(33,34)$ and its role in alveolar epithelial barrier function (38). Although Claudin 7 behaved similarly to our prior study, demonstrating only a modest induction of RNA and no significant change in protein content over $24 \mathrm{~h}$, it was remarkable that localization of Claudin 7 became directed to the plasma membrane with stretch. Studies of rat type I cell transdifferentiation also observed an increase in Claudin 7 that was maximal after $7 \mathrm{~d}$ in culture, with a more plasma membrane distribution in type I cells that correlated with increased barrier function (39). The silastic membranes we used for the static stretch in our system precluded a more functional approach to assessing barrier function. However, redistribution of Claudin 7 is indirect but consistent evidence of enhanced barrier function with stretch. Taken together, changes in type I and II cell marker expression clearly show that despite culture conditions that support maintenance of type II cell phenotype, stretch fosters change toward a type I cell phenotype in HFL epithelial cells. 
Several signal transduction pathways have been implicated in stretch-mediated lung maturation, including extracellular signal related kinases (24), protein kinase A and C (2), heparin-binding epidermal growth-like factor, and transforming growth factor alpha (40). The Rho/ROCK pathway is an excellent candidate for transmitting alveolar epithelial cell stretch into gene expression due to its pivotal role in regulating the actin cytoskeleton, and in mechanotransductionmediated differentiation, most notably in smooth muscle cells (41). We provide compelling evidence that Rho pathway activation plays an important role in static stretch-induced differentiation of HFL epithelium: indirectly by the increase in stress fibers with static stretch and directly by detecting GTPbound Rho within $15 \mathrm{~min}$ of applying static stretch. More importantly, stretch-induced changes in epithelial cell marker expression were blunted in the presence of a specific Rho inhibitor, Y27632. Our data echo similar observations in rodent type II cells, with the ROCK inhibitor H-1152 blunting the effect of cyclic stretch on expression of the type II cell marker SP-C (19). Similar to their studies, our data show that Rho A is a negative regulator of type II cell markers, especially at reduced levels of stretch-5\% in their study, and 10\% in ours. What is more impressive is that Rho A is a positive regulator of type I cell markers at both levels of stretch in this study, placing the Rho pathway as a central regulator of alveolar epithelial differentiation in response to stretch. The differences in response between type I and type II markers and between 10 and $37 \%$ stretch may reflect events downstream of Rho A. Y27632 is a ROCK inhibitor, which will account for only one limb of the pathway after Rho A activation leading to inhibition of cofilin and promoting actin polymerization (23). Because an intact cytoskeleton is a critical factor in mediating mechanotransduction, the role of profilin actions could be important but are not regulated by ROCK and thus not susceptible to Y27632. The inability of ROCK inhibition to restore type II cell marker expression to unstretched levels illustrates that there are additional mechanotransduction pathways involved, such as the mitogen-activated protein kinase pathway (24). The resultant intermediate type I/II cell phenotype may simply reflect the short duration of these experiments. However, they suggest a reasonable explanation for the presence of such intermediate cells observed by others in response to lung injury as repopulating type II cells begin to transdifferentiate $(26,42,43)$. Although there is increasing evidence of type I to type II cell plasticity (44), it remains unclear whether this is stretch-responsive in vivo and which pathways might be involved.

In summary, we have shown that static stretch is an important determinant of alveolar epithelial cell plasticity and that mechanotransduction is partially mediated by the Rho pathway. The Rho GTPase pathway may provide an important early indicator of alveolar epithelial cell well being in studies designed to evaluate lung-protective ventilation strategies and may offer a targeted pathway for the design of novel pharmacologic interventions, due to the accessibility of the alveolar epithelium, to prevent lung injury during mechanical ventilation.
Acknowledgments. We thank Ping Wang for cell preparation and James Hayden and Frederick Keeney, from the Wistar Institute Microscopy Facility for assistance with the stress fiber imaging and image quantitation studies.

\section{REFERENCES}

1. Guttentag SH, Ballard PL 2005 Lung development: embryology, growth, maturation, and developmental biology. In: Taeusch HW, Ballard RA, Gleason CA (eds) Avery's Diseases of the Newborn. Elsevier Saunders, Philadelphia, PA, pp 601-615

2. Liu M, Post M 2000 Invited review: mechanochemical signal transduction in the fetal lung. J Appl Physiol 89:2078-2084

3. Kitterman JA 1996 The effects of mechanical forces on fetal lung growth. Clin Perinatol 23:727-740

4. Harding R, Liggins GC 1996 Changes in thoracic dimensions induced by breathing movements in fetal sheep. Reprod Fertil Dev 8:117-124

5. Martin TR 2008 Interactions between mechanical and biological processes in acute lung injury. Proc Am Thorac Soc 5:291-296

6. Tschumperlin DJ, Margulies SS 1999 Alveolar epithelial surface area-volume relationship in isolated rat lungs. J Appl Physiol 86:2026-2033

7. Rotschild A, Ling EW, Puterman ML, Farquharson D 1990 Neonatal outcome after prolonged preterm rupture of the membranes. Am J Obstet Gynecol 162:46-52

8. Page DV, Stocker JT 1982 Anomalies associated with pulmonary hypoplasia. Am Rev Respir Dis 125:216-221

9. Yoshizawa J, Chapin CJ, Sbragia L, Ertsey R, Gutierrez JA, Albanese CT, Kitterman JA 2003 Tracheal occlusion stimulates cell cycle progression and type I cell differentiation in lungs of fetal rats. Am J Physiol Lung Cell Mol Physiol 285:L344L353

10. Adzick NS, Harrison MR, Glick PL, Villa RL, Finkbeiner W 1984 Experimental pulmonary hypoplasia and oligohydramnios: relative contributions of lung fluid and fetal breathing movements. J Pediatr Surg 19:658-665

11. Kitterman JA, Chapin CJ, Vanderbilt JN, Porta NF, Scavo LM, Dobbs LG, Ertsey R, Goerke J 2002 Effects of oligohydramnios on lung growth and maturation in the fetal rat. Am J Physiol Lung Cell Mol Physiol 282:L431-L439

12. Khan PA, Cloutier M, Piedboeuf B 2007 Tracheal occlusion: a review of obstructing fetal lungs to make them grow and mature. Am J Med Genet C Semin Med Genet 145C: $125-138$

13. Dobbs LG, Gutierrez JA 2001 Mechanical forces modulate alveolar epithelial phenotypic expression. Comp Biochem Physiol A Mol Integr Physiol 129:261-266

14. Sanchez-Esteban J, Wang Y, Filardo EJ, Rubin LP, Ingber DE 2006 Integrins beta1, alpha6, and alpha3 contribute to mechanical strain-induced differentiation of fetal lung type II epithelial cells via distinct mechanisms. Am J Physiol Lung Cell Mol Physiol 290:L343-L350

15. Ingber DE 2003 Tensegrity II. How structural networks influence cellular information processing networks. J Cell Sci 116(Pt 8):1397-1408

16. Moore KA, Polte T, Huang S, Shi B, Alsberg E, Sunday ME, Ingber DE 2005 Control of basement membrane remodeling and epithelial branching morphogenesis in embryonic lung by Rho and cytoskeletal tension. Dev Dyn 232:268-281

17. Olivera DS, Boggs SE, Beenhouwer C, Aden J, Knall C 2007 Cellular mechanisms of mainstream cigarette smoke-induced lung epithelial tight junction permeability changes in vitro. Inhal Toxicol 19:13-22

18. Desai LP, Chapman KE, Waters CM 2008 Mechanical stretch decreases migration of alveolar epithelial cells through mechanisms involving Rac1 and Tiam1. Am J Physiol Lung Cell Mol Physiol 295:L958-L965

19. Silbert O, Wang Y, Maciejewski BS, Lee HS, Shaw SK, Sanchez-Esteban J 2008 Roles of RhoA and Rac1 on actin remodeling and cell alignment and differentiation in fetal type II epithelial cells exposed to cyclic mechanical stretch. Exp Lung Res 34:663-680

20. Gonzales LW, Angampalli S, Guttentag SH, Beers MF, Feinstein SI, Matlapudi A, Ballard PL 2001 Maintenance of differentiated function of the surfactant system in human fetal lung type II epithelial cells cultured on plastic. Pediatr Pathol Mol Med 20:387-412

21. Foster C, Aktar A, Kopf D, Zhang P, Guttentag S 2004 Pepsinogen C: a type 2 cell-specific protease. Am J Physiol Lung Cell Mol Physiol 286:L382-L387

22. Bishop AL, Hall A 2000 Rho GTPases and their effector proteins. Biochem J 348(Pt 2):241-255

23. Hellstrand P, Albinsson S 2005 Stretch-dependent growth and differentiation in vascular smooth muscle: role of the actin cytoskeleton. Can J Physiol Pharmacol 83:869-875

24. Sanchez-Esteban J, Wang Y, Gruppuso PA, Rubin LP 2004 Mechanical stretch induces fetal type II cell differentiation via an epidermal growth factor receptorextracellular-regulated protein kinase signaling pathway. Am J Respir Cell Mol Biol 30:76-83

25. Danzer E, Davey MG, Kreiger PA, Ruchelli ED, Johnson MP, Adzick NS, Flake AW, Hedrick HL 2008 Fetal tracheal occlusion for severe congenital diaphragmatic hernia in humans: a morphometric study of lung parenchyma and muscularization of pulmonary arterioles. J Pediatr Surg 43:1767-1775

26. Flecknoe S, Harding R, Maritz G, Hooper SB 2000 Increased lung expansion alters the proportions of type I and type II alveolar epithelial cells in fetal sheep. Am J Physiol Lung Cell Mol Physiol 278:L1180-L1185

27. Adamson IY, Bowden DH 1975 Derivation of type 1 epithelium from type 2 cells in the developing rat lung. Lab Invest 32:736-745

28. Evans MJ, Cabral LJ, Stephens RJ, Freeman G 1975 Transformation of alveolar type 2 cells to type 1 cells following exposure to NO2. Exp Mol Pathol 22:142-150 
29. Borok Z, Hami A, Danto SI, Zabski SM, Crandall ED 1995 Rat serum inhibits progression of alveolar epithelial cells toward the type I cell phenotype in vitro. Am J Respir Cell Mol Biol 12:50-55

30. Williams MC, Cao Y, Hinds A, Rishi AK, Wetterwald A 1996 T1a protein is developmentally regulated and expressed by alveolar type I cells, choroid plexus, and ciliary epithelia of adult rats. Am J Respir Cell Mol Biol 14:577-585

31. Gutierrez JA, Gonzalez RF, Dobbs LG 1998 Mechanical distension modulates pulmonary alveolar epithelial phenotypic expression in vitro. Am J Physiol 274:L196-L202

32. Williams MC 2003 Alveolar type I cells: molecular phenotype and development Annu Rev Physiol 65:669-695

33. Daugherty BL, Mateescu M, Patel AS, Wade K, Kimura S, Gonzales LW, Guttentag S, Ballard PL, Koval M 2004 Developmental regulation of claudin localization by fetal alveolar epithelial cells. Am J Physiol Lung Cell Mol Physiol 287:L1266L1273

34. Foster CD, Varghese LS, Skalina RB, Gonzales LW, Guttentag SH 2007 In vitro transdifferentiation of human fetal type II cells toward a type I-like cell. Pediatr Res 61:404-409

35. Gonzales LW, Guttentag SH, Wade KC, Postle AD, Ballard PL 2002 Differentiation of human pulmonary type II cells in vitro by glucocorticoid plus cAMP. Am J Physiol Lung Cell Mol Physiol 283:L940-L951

36. Bates SR, Gonzales LW, Tao JQ, Rueckert P, Ballard PL, Fisher AB 2002 Recovery of rat type II cell surfactant components during primary cell culture. Am J Physiol Lung Cell Mol Physiol 282:L267-L276
37. Dobbs LG, Pian MS, Maglio M, Dumars S, Allen L 1997 Maintenance of the differentiated type II cell phenotype by culture with an apical air surface. Am J Physiol 273:L347-L354

38. Van Itallie CM, Anderson JM 2004 The molecular physiology of tight junction pores. Physiology (Bethesda) 19:331-338

39. Chen SP, Zhou B, Willis BC, Sandoval AJ, Liebler JM, Kim KJ, Ann DK, Crandall ED, Borok Z 2005 Effects of transdifferentiation and EGF on claudin isoform expression in alveolar epithelial cells. J Appl Physiol 98:322-328

40. Wang Y, Maciejewski BS, Soto-Reyes D, Lee HS, Warburton D, Sanchez-Esteban J 2009 Mechanical stretch promotes fetal type II epithelial cell differentiation via shedding of HB-EGF and TGF-alpha. J Physiol 587(Pt 8):1739-1753

41. Owens GK, Kumar MS, Wamhoff BR 2004 Molecular regulation of vascular smooth muscle cell differentiation in development and disease. Physiol Rev 84:767-801

42. Clegg GR, Tyrrell C, McKechnie SR, Beers MF, Harrison D, McElroy MC 2005 Coexpression of RTI40 with alveolar epithelial type II cell proteins in lungs following injury: identification of alveolar intermediate cell types. Am J Physiol Lung Cell Mol Physiol 289:L382-L390

43. Olsen CO, Isakson BE, Seedorf GJ, Lubman RL, Boitano S 2005 Extracellula matrix-driven alveolar epithelial cell differentiation in vitro. Exp Lung Res 31:461482

44. Gonzalez RF, Allen L, Dobbs LG 2009 Rat alveolar type I cells proliferate, express OCT-4, and exhibit phenotypic plasticity in vitro. Am J Physiol Lung Cell Mol Physiol 297:L1045-L1055 